\title{
Identification and Development of Patron Personas for an Academic Library
}

\author{
Holt Zaugg \\ Brigham Young University, holt_zaugg@byu.edu \\ Scott Rackham \\ rackhams@mac.com
}

Follow this and additional works at: https://scholarsarchive.byu.edu/facpub

Part of the Library and Information Science Commons

\section{Original Publication Citation}

Zaugg, H., \& Rackham, S. (2016). Identification and development of patron personas for an academic library, Performance Measurement and Metrics, 17(2), 124-133.

\section{BYU ScholarsArchive Citation}

Zaugg, Holt and Rackham, Scott, "Identification and Development of Patron Personas for an Academic Library" (2016). Faculty Publications. 1808.

https://scholarsarchive.byu.edu/facpub/1808 
Identification and Development of Patron Personas for an Academic Library

Holt Zaugg, BYU

Scott Rackham, BYU 


\begin{abstract}
Purpose. Ranganathan's Laws of Library Science and continued refinements to his initial laws place identification of patron's needs and connection of those needs to library services of primary importance in libraries (Ranganathan, 1931; Crawford \& Gorman, 1995; Noruzi, 2004). Identifying and developing personas or user group descriptions helps to identify the unique nature of library patrons. Each persona helps librarians to identify or create services specific to the persona of library patrons. As each library persona is better understood, the library faculty and staff are able to prepare and plan for service delivery. Initially personas were developed for undergraduate students followed by the identification and development of personas for graduate students and faculty. This paper focuses on the identification and development of the undergraduate patron personas.
\end{abstract}

Design, methodology or approach. The identification and development of undergraduate patron personas engaged communications students, as part of their coursework, to use a review of previous studies to develop theories of library patron personas. Each of the three groups within the communications class verified their initial persona theories using surveys, focus groups, interviews, observations and ethnographic methods. All personas from each group was further developed and refined into a final list and description of 10 library personas. A principal components analysis helped to provide interconnections between the personas and estimate the percent of patrons each persona comprised.

Findings. The study identified 10 personas (user groups) who use a wide variety of library services. Descriptions of personas enabled library faculty and staff to identify personas accessing their services, to further develop and refine current services and to create new services to meet the needs of patrons.

A principle components analysis further facilitated the understanding of interrelations between the personas based on persona use of library services. Personas that had common needs or use patterns were grouped together to further understanding of patrons use patterns and needs. While an attempt was made to determine the percent of total patrons each persona was, evidence was found that indicated the fluid nature of personas in regards to library services. That is, as the patron needs shifted, so did their persona. Patrons moved from one persona to another to meet their shifting needs as the academic semester proceeded.

Research or practical limitations or implications. The identification and description of personas has several practical implications for librarians. First, when the personas enable librarians to reflect on the services they provide in terms of specific personas. This reflection enables the refinement and development of library services to meet patron needs. Second, understanding of the interconnection of persona needs enables librarians to market other services. For example, as a patron uses one service, librarians are able to point out related services that may be of interest or help to the patron. This becomes of particular importance for orientation tours of new students to the university. Finally, matching the personas with other library trends and patterns assists librarians with the development of the library as a space suited to meet the needs of its patrons. 
Several limitations to this study exist. First, as mentioned earlier, patrons often identified with several types of patron descriptions over the course of a semester. This makes predicting what percent of the total patrons each persona is quite difficult. While initial efforts provided an estimate of the percent of total for each persona, there needs to be a method developed to determine how personas change throughout the semester and when. Second, the identification and description of undergraduate patron personas only examined the persona found within the physical library. One persona, the Outsider, in all likelihood consists of several sub-personas who use library services, but rarely, if ever, come to the physical library. Further work needs to be done to identify and describe the Outsider persona. Finally, as the personas are fluid within a semester among patrons, it is also believed that personas will change as the library services and facility changes. This may result in the increased importance of some personas, the decreased importance of other personas and the development of new personas to describe emerging patron needs. A time table needs to be identified whereby the undergraduate patron personas may be revisited to determine any changes.

Conclusions. The development of undergraduate patron personas provides insights into how patrons are accessing library services. These insights enable librarians to plan and to deliver services better. It provides the opportunity for patrons to be informed of the full range of library services that may assist them in their education and personal needs. As such personas become a powerful tool to better develop and deliver library services.

Originality and value of the proposal. While the use of personas is common in communications, marketing and business, their development and use in academic libraries is quite unique. They become quite useful in associating library services to the patrons that use them. Strategic planning also uses personas as services are upgraded and improved or new services are created to meet more persona needs. 


\section{Identification and Development of Patron Personas for an Academic Library}

\section{Introduction}

Ranganathan's laws of library science and continued refinements to his initial laws place importance on identifying patrons' needs and connecting those needs to library services (Crawford and Gorman, 1995; Noruzi, 2004; Ranganathan, 1931). At academic libraries, meeting the needs of all students and faculty members can be a daunting task. Trying to meet the needs of each patron spreads library resources and personnel so thin that no one is truly served. The task then becomes how to group the diverse patrons into a more manageable size.

When examined closely, patrons form groups with common needs and patterns of library use. The process of identifying common needs and use patterns among patrons enables librarians to group thousands of patrons within a description that presents the group's needs and use patterns as if the group were a single person, or a persona? (Guenther, 2006; Mckay, 2010; Pruitt and Grudin, 2003; Schmidt, 2014). While persona development is often used in business and product marketing, its use in not-for-profit enterprises, such as libraries, is rarer. This study describes the efforts at the Harold B. Lee Library (HBLL) at Brigham Young University (BYU) to identify and describe the personas of library patrons. The study has three phases, the identification and development of patron personas, the validation of library personas, and how personas may be used to facilitate the delivery of library services.

\section{Literature Review}

Personas have long been used in marketing and design work to facilitate the communication or development of specific products used by customers (Guenther, 2006; Mckay, 2010; Schmidt, 2014). The intent behind the development of personas is to identify user behaviors and needs so that patrons' needs may be met. Typically a persona includes a description of an imaginary person, including a picture, background information, and use patterns wrapped up in a file that describes the persona as if he or she were a real person. While much of this information is based on collected data, details may be fleshed out to provide a more personalized intimate and precise description of the persona (Cunningham, 2005; Idoughi et al., 2012). While a wide variation of persona descriptions exists, depending on the circumstance or service associated with each persona, a persona typically provides a description of how the user interacts with a specific product or service (Leary and Allen, 2011).

Identification and development. The process of creating personas primarily uses qualitative methods, such as formal and informal interviews and observations of patrons (Bilandzic and Foth, 2013; Blomquist and Arvola, 2002). However other data sources may be used; for instance, Tempelman-Kluit and Pearce (2014) used a log of library chat conversations to create four personas. While qualitative data is used predominantly, quantitative data (e.g., surveys) may also be used as long as it indicates how patrons use a service or express a need. AlShboul and Abrizah (2014) point out that other anecdotal evidence from assessments should be ignored when identifying and developing personas. As long as each data set contributes evidence of use patterns and expressed needs, the data becomes valuable in creating a richer persona description.

Validation. Once personas are created, they need to be validated and refined. In this process researchers continue to use qualitative methods to identify personas but quantitative methods may also be used (Mulder and Yaar, 2007). Several studies, using validation data from surveys, have used principal component analysis (PCA) to further refine the persona clusters 
(Blomquist and Arvola, 2002; Hellstrom and Eriksson, 2013). The intent is to be able to enhance the persona description through refinements, further elaborations, and connections with other personas or services. This is similar to the Amazon marketing tool of "people who bought $\mathrm{X}$ also bought Y." In the case of personas, it would be "personas who used X service also used Y service."

Implementation. Once created, personas should become an integral part of service delivery and strategic plans. When modifying a current service or creating a new service, personas are used to focus design changes. Questions such as, "How would X use this service?" assist planners and developers to make key strategic decisions and to evaluate the inevitable tradeoffs (Olsen, 2004). Personas focus efforts to make better tactical decisions in the provision of services and products. They may also be used as a check when a change is made that confirms the value and quality of the service or product (Fourie and Fourie, 2014).

For personas to be infused throughout the organization, several steps need to be taken to avoid misuse and confusion. Pruitt and Grudin (2003) indicate that personas must be believable. Their use patterns and needs must be communicated clearly. Finally, there needs to be support for using the personas throughout the entire staff - from the front-line employees to library leadership. Pruitt and Grudin (2003) caution that personas should not be used outside of the context in which they were created. As more information is provided, personas may be refined, much like our understanding of people who start as associates and become close confederates. When a persona no longer becomes relevant for the purpose it was created, it should be abandoned.

This study seeks to describe the process of persona development, validation, and implementation at the HBLL. The paper will describe how the personas were created, including a description of each persona, steps taken to validate the personas, and, finally, how the personas are being integrated into the library's planning and design efforts.

\section{Method}

Students from a fourth year communications class were enlisted to help with the identification and development of personas as part of their course work (Washburn and Bibb, 2011). As an initial step, library personnel met with the course instructor and students to discuss the desired outcomes and scope of the project. All students were required to complete Institutional Review Board (IRB) training to certify them as research assistants as part of their course project. Once students were certified, the library provided de-identified raw data from assessment projects involving undergraduate students over the past five years. Using this data and working in three separate teams, student researchers developed initial personas with names and descriptions

As a final step in the persona development, students identified gaps in their personas and made requests for further data collection. Amendments to the initial IRB submission allowed for new data to be collected using observations, focus groups, interviews, and ethnographic studies. Not all data collection methods were used by each team. For example, one team conducted focus groups while another used interviews.

Once additional data was collected and analyzed, the initial personas were revised, some personas were combined, others deleted or added making the descriptions better. Following this revision, student teams presented their personas to the entire communications class and the assessment librarian. As presentations were made, the non-presenters would ask questions for 
clarification to help each group refine their personas. Finally, each group presented their finished personas to the library administration. Following this presentation, the assessment librarian streamlined the efforts of the individual teams; for example, when two or more teams described the same persona but used different names, those descriptions were combined into a single persona. After this process, a total of 10 undergraduate student personas were identified.

Using the 10 personas, the assessment librarian created a single statement for each persona. The statement was made in first person and summarized the typical behavior of the persona. Undergraduate students were then surveyed to identify which single statements best exemplified their use of the library. It should be noted that students were only allowed to choose one of the 10 personas as their dominant persona. These findings were used to further refine the personas into common clusters using PCA. The survey also sought demographic data (i.e., gender, school or college of major, and year at university) to determine if the survey respondents matched the general university population.

\section{Results}

Persona Descriptions. Each of the 10 undergraduate personas identified were given a name: Explorer, Collaborator, Focuser, Side-Kicks, Socializer, Islander, Chillaxer, In-n-Outer, Pirate, and Outsider. A detailed description of each of these personas is provided, followed by discussion on the validation of the personas.

Explorer. The Explorer persona, identified by two of the three student groups, describes patrons who come to the library to discover new things that are not tied to any particular assignment. The discovery may focus on physical items or on special lectures or performances. This persona is motivated by a desire to find out and learn new things. Patrons in this group are characterized by the quotes:

I just like libraries in general. I like being able to find random things, for example the 4th floor music history library is cool, and the place where they have vinyl records, I'd go there to relax and listen to the vinyl records.

The library has nice stuff, and a lot of resources, they've got the best types of cameras and stuff to check out.

Collaborator. Two of the three student groups identified this persona. Patrons in this persona are motivated to get good grades and view collaboration as a means to this end. There are two types of collaborators: The first type is an involuntary collaborator where students taking a common course are put together in a group to complete a task or assignment as a part of that course. The second type is a voluntary collaborator where patrons who know each other form a study group to work on course assignments. The size of the collaboration group will vary depending on the class, the assignment, and the number of known friends. These patrons are often found in group study rooms and locations where they can openly talk and visit with one another. A comment typical of this persona is:

I do use group rooms a lot. I have had a lot of group projects, or just study groups, so we'll reserve a group study room.

Focuser. Identified by all student groups, this persona describes students seeking to get an A grade in every course. Patrons in this persona prefer to study by themselves with no noise, distractions, or interruptions. They seek out areas that are quiet. This may include areas with poor cell phone reception or areas that are known to be quieter. Focusers commonly use the individual study cubicles and even reserve group study rooms for themselves because of the quiet and isolating atmosphere. A comment indicative of Focusers is: 
When I'm in the library I feel like I'm more effective, even if that's not true. My mind knows

I'm here to study whereas if I'm at my house I don't study. My mind associates studying with the library.

Side-Kicks. The Side-Kick persona was identified by all student groups. Like the Focuser, this persona is also a dedicated studier; however, this persona is a blend between the Focuser and the Collaborator. Patrons in this persona are dedicated to studying but like to be with another person. These patrons sit with a friend, but they are not studying the same material. Having a friend nearby helps to keep them focused and motivated to work on their assignments.

Comments typical of Side-Kicks are:

Usually the same amount of work gets done when I'm with a roommate, they just help me not be so lonely.

When I see other students studying, it gives me the feeling that they are being responsible and working hard so I should too.

Socializer. Identified by all three student groups, this persona's primary motivation is to meet new people and to visit with friends. Patrons in this persona come to the library to relax when they have a short break between classes or even specifically to meeting people. They are often very talkative and loud. While some studying may occur, their primary purpose for coming to the library is to socialize and flirt. A typical comment is:

I've tried to get dates on the 4th floor before. I've had about a 50/50 success rate. I've gone to flirt before.

Islander. Identified by only one student group, Islanders describe a persona who has a specific location that meets his or her study needs. Location is the key indicator for this persona because it matches their personality and needs when using the library. While some Islanders may pick an area with limited noise (i.e., the classical music area), most have a place where they can focus on studying or other individual activities that may or may not be related to class work (e.g., writing, drawing, reading a personal book). Typical comments are:

I love that there's classical music playing because it helps me study and relax. I feel like it is my main area of the library.

You can find your own spot where no one can bother you.

Chillaxer. Identified by two student groups, this persona enjoys the combination of services and atmosphere provided in the library. These patrons have a blend of study and fun. They feel comfortable enough to watch YouTube, play video games, or take a nap as a break from studies. They are often found in the Media Center, using a viewing room to watch a DVD. A typical comment was:

I like to come to the library instead of the CADM lab to do my engineering assignments because the Internet is faster. When I get tired, I take breaks to watch YouTube.

In-n-Outer. This persona typically comes for a specific, short-term purpose in the library and then leaves. For example, In-n-Outers come to print a paper for an assignment, pick up a book or other item that is on hold, or obtain some type of information before leaving. These patrons spend as little time in the library as possible. While they recognize the library as a place to use or access resources, they do not wish to spend any more time than necessary in the library. $\mathrm{He} / \mathrm{she}$ comes to the library, accesses the resources, and leaves. No quotes typical of the group were collected.

Pirate. This persona uses the library resources for convenience. Pirates typically bring a flash drive and use the library computers so they do not need to bring their computer to school. They may also use the computers to access social networks. Their focus is to use a library tool or 
resource so they do not need to buy or bring that tool. These patrons are typically found in the computer labs using software for classes or personal activities. A quote typical of this persona is:

Why would I buy my own laptop if I can use a computer here?

Outsider. This persona was a known entity, but was not directly observed since they are not found in the library. However, it includes two specific subgroups. The first subgroup is those patrons who are intimidated by or feel a tension or anxiousness in the library. This is considered to be a very small subgroup, though no direct evidence of its size has been collected. The second and dominant Outsider subgroup includes students who access library services virtually. They are focused on getting things done, but have another location on campus or at home that is more convenient to use. While it is possible that other subgroups exist, this study did not identify any further subgroups. A comment typical of this group is:

I feel like it is so quiet. I don't need to use the books, and everything I need is on my computer. I can't eat in there, I can't mess anything up. I don't go to the library.

Validation. The single statement per persona survey was used to determine what percentage of the total population each persona represents. If an even balance existed between personas, each persona would represent about $10 \%$ of the total. The validation data indicated that some personas were more dominant than others. Three personas (Islanders 26\%, Focusers 18\%, and Pirates 18\%) represent a high percentage of patron use. Two personas (Collaborators 10\% and Side-Kicks 11\%) are at the expected range. Collectively, these five personas make up $83 \%$ of undergraduate library patrons. Of the remaining personas, three (Explorers, In-n-Outers, and Outsiders) each represent 5\% of the HBLL's undergraduate patrons. Finally, two personas (Socializers and Chillaxers) only represent $1 \%$ of HBLL patrons, but because of location, activities, and noise levels, they are often noticed more. Table 4 provides the percentage of students sampled described by each persona.

Table 4. Persona percentage of total undergraduate student patrons.

\begin{tabular}{lc} 
Persona & Percent of Total \\
\hline Islanders & 26 \\
Focusers & 18 \\
Pirates & 18 \\
Side-Kicks & 11 \\
Collaborators & 10 \\
Explorers & 5 \\
In-n-Outers & 5 \\
Outsiders & 5 \\
Socializers & 1 \\
Chillaxers & 1 \\
\hline
\end{tabular}

Using the data collected from this survey, a PCA was conducted. The PCA is a statistical method used to determine how difficult-to-measure constructs (such as personas) correlate with one another. In this case, it puts correlated personas into common clusters. These clusters are commonly referred to as components since they consist of two or more personas that correlate to one another in some way.

The PCA situated the personas into four components with a common theme uniting each component. In this case, the persona components include social-oriented, task-oriented, collaboration-oriented, and tool-oriented components. Each component is described below. 
Social-oriented. This component includes the Explorer, Socializer, and Chillaxer personas. They are typified by activities within the library that are not focused on a specific academic goal but that may have an academic component. The academic component is not the primary or sole focus of this component. They seek to interact with other people or materials that they find interesting.

Task-oriented. This component includes the Focusers, Islanders, and Outsiders. Of interest is the moderate, negative correlation between the Outsider persona and the Focuser and Islander personas. The moderate correlation indicates a strong connection with the other two personas, but in an opposite way. The negative correlation is taken to indicate a different use of library services. Whereas the Focuser and Islander activities are located within the library, the Outsider accesses library services online. The emphasis of this component is finding a means to complete a task (e.g., studying, writing) in as efficient and effective a manner as possible.

Collaboration-oriented. The Collaborator and Side-Kick personas constitute this component. They are noted for working with others. While they are focused on getting school work done, the key is that they gain something by being in proximity to others whether they are working on the same task or not. They seek a space that enables them to have this personal contact.

Tool-oriented. The Pirate and In-n-Outer personas constitute this component. They are characterized by using tools and services in the library where students may either quickly enter, obtain what they need, and then leave (e.g., printing, circulation holds) or may stay and use services or materials here in the library (e.g., computer labs). Either way, the patron views the library as a tool provider.

\section{Limitations}

Several limitations are of note in this study. First, the personas were developed by three different groups and combined to make the final 10 personas. Some personas were only identified by one of the three student groups. Further examination may be needed to determine if these personas could or should be merged into another persona.

Second, the personas were only developed for undergraduate students who physically attended the HBLL. One persona, Outsiders, describes students who do not physically attend the library, but this persona have more sub-divisions. Also the study focused solely on undergraduate students. Graduate student and faculty personas need to be developed. It is anticipated that some of faculty and graduate student personas will be similar to undergraduate students, but, different personas are anticipated. The Outsider persona and faculty and graduate student personas need to be further developed.

Third, the validation process provided percentages of the dominant persona for undergraduate students. Subsequent validation efforts indicated that patrons switch personas depending on circumstances. For example, Focusers may become In-n-Outers when they simply need to print a paper. A second validation effort is needed to determine the total percent of the patron population each persona represents. This will provide more evidence of the fluid nature of personas as undergraduate students move through a variety of learning activities in the semester. Switching personas depending on circumstance is supported by Leary and Allen (2011). They describe users who develop a repertoire of personas that may be used to help meet their needs depending on the situation. 


\section{Implementation}

Several steps are essential to the implementation of personas. The persona description must be believable and accurate. Library personnel need to recognize, believe, and trust the personas (Blomquist and Arvola, 2002; Pruitt and Grudin, 2003). The background and name of the persona should also reflect who that patron is. For example, in this case, general names, rather than specific names, were given to the personas because there was a lack of evidence that a persona was uniquely male or female. In addition, a great deal of background information was not provided because of the similarity of university students. It was also felt that such extra, unsubstantiated information would undermine the credibility of the personas with library employees.

The second phase of implementation involves employees adopting persona vision when providing, modifying, or developing library services and products. Persona vision refers to seeing services and products through the eyes of library personas. Personas are identified as primary and potential clients. For example, when designing new individual study carrels, one employee noted that if left-handed and right-handed were fit together, the carrels could serve as a pod for two or three students to collaborate meeting the needs of the Islander, Collaborator, and Side-kick personas. As library employees gain persona vision, they begin to see who their service targets and what makes that service more effective.

In other cases, library employees may use the clusters of personas described in the PCA to combine or improve services. For example, if circulation and reference desks serve a persona in a similar cluster, combining the circulation and reference services would enable the library employees to cross-pollinate service delivery and make patrons aware of more services and products offered by the library. Such cross pollination opportunities do not require library services to be combined, rather simply to be aware of and promote one another to increase the service delivery to patrons (Hellstrom and Eriksson, 2013).

The third phase of implementation involves adapting assessments, made to determine the efficacy of specific library services and products, to include persona vision. The personas become a validation method of a specific service. For example, if an evaluation of a service indicates that it is used by Focuser and Islander personas, the library can indicate that the product serves about $44 \%$ of the patrons. This substantiates the value of the service and aids in the creation or elimination of specific library services when tough planning decisions must be made (Fourie and Fourie, 2014; Olsen, 2004)

Aspects of evaluations may also be framed in terms of personas. For example, after a recent administration of the LIBQual ${ }^{+\circledR}$ survey, patrons' comments from the survey were categorized, where possible, into specific personas. The library can determine what each persona is saying and if changes have helped or hindered the delivery of library services and products. In this way, personas become another way to disaggregate the data to focus on how specific library services and products are meeting the needs of patrons. It also provides insights into how the services and products may be developed and improved.

A final consideration is how personas may be misused. It is relatively easy for people to begin to stereotype patrons into a single persona. Instead, patrons should be viewed as having a repertoire of personas that help them to move smoothly and successfully through a variety of situations (Leary and Allen, 2011). In this way each persona becomes a single facet of who the patron is. Meeting the needs of as many of the facets indicates a greater value of library service to each patron. 
A word of caution must also be given to ensure that the personas developed in one context may or may not be similar to those found in another. For example, the personas present in an academic library may or may not match those found in a public or private library. Personas developed for one academic library may or may not be found in other patrons. For example, graduate students and faculty may have both similar and dissimilar personas as undergraduate students because of their focus and research needs. Care needs to be taken that personas are not used out of the context for which they were created.

\section{Conclusion}

While personas were initially created primarily for use in advertising and product design, they show great potential for use within academic libraries. Personas offer a simplified view of patrons that enables librarians to refine how library products and services assist patrons and bless their lives. Personas may be used to indicate the value of current products and services, and they offer a unique perspective to aid librarians in making difficult decisions and trade-offs. Library employees can use personas to focus meaningful conversations related to how library departments and employees may work better together to improve service to patrons. 


\section{References}

Al-Shboul, M.K. and Abrizah, A. (2014), "Information needs: Developing personas of humanities scholars", The Journal of Academic Librarianship, Vol. 40 No. 5, pp. 500-509.

Bilandzic, M. and Foth, M. (2013), "Libraries as coworking spaces”, Library Hi Tech, Vol. 31 No. 2, pp. 254-73.

Blomquist, A. and Arvola, M. (2002), "Personas in action: Ethnography of an interaction design team", Proceedings of the Second Nordic Conference on Human-Computer Interaction, Vol. 31, pp. 197-200.

Crawford, W. and Gorman, M. (1995), Future Libraries: Dreams, Madness \& reality. American Library Association, Chicago, IL.

Cunningham, H. (2005), "Designing a website for one imaginary persona that reflects the needs of the many", Computers in Libraries, Vol. 25 No. 9, pp. 15-19.

Fourie, I and Fourie, H. (2014), "Targeting users in information provision-more than researchers, students and professionals", Library Hi Tech, Vol. 32 No. 1, pp. 164-72.

Guenther, K. (2006), “Developing personas to understand user needs”, Online, Vol. 30 No. 5, pp. 49-51.

Hellstrom, A. and Eriksson, H. (2013), “Among fumblers, talkers, mappers and organisers: Four applications of process orientation”, Total Quality Management, Vol. 24 No. 6, pp. 733-51.

Idoughi, D., Seffah, A., and Kolski, C. (2012), “Adding user experience into the interactive service design loop: A persona-based approach", Behavior \& Information Technology, Vol. 31 No. 3, pp. 287-303.

Leary, M.R. and Allen, A.B. (2011), "Self-presentational persona: Simultaneous management of multiple impressions", Journal of Personality and Social Psychology, Vol. 101 No. 5, pp. 103349.

Mckay, L. (2010), "Adding the persona touch: With an eye on the user experience, some brands are inviting imaginary friends to the party", CRM Magazine, Vol. 14 No. 2, pp. 19-20.

Mulder, S. and Yaar, Z. (2007), "Approaches to creating personas”, in Mulder, S., The User Is Always Right: A Practical Guide to Creating and Using Personas for the Web. New Riders, Berkeley, CA. pp. 1-10.

Noruzi, A. (2004), “Application of Ranganathan's Laws to the Web”, Webology, Vol. 1 No. 2 , Article 8.

Olsen, G. (2004), "Making personas more powerful: details to drive strategic and tactical design", available at: http://boxesandarrows.com/making-personas-more-powerful-details-todrive-strategic-and-tactical-design (accessed 7 March 2015). 
Pruitt, J. and Grudin, J. (2003), "Personas: Practice and theory", DUX '03: Proceedings of the 2003 Conference on Designing for User Experience, San Francisco, CA., June 5-7, 2003, pp. 115.

Ranganathan, S. R. (1931), The Five Laws of Library Science, Edward Goldston, London, England.

Tempelman-Kluit, N. and Pearce, A. (2014), "Invoking the user from data to design", College \& Research Libraries, Vol. 75 No. 5, pp. 616-40.

Washburn, A. and Bibb, S. (2011), "Students studying students: An assessment of using undergraduate student researchers in an ethnographic study of library use", Library and Information Research, Vol. 35 No. 109, pp. 55-66. 